\title{
BEAUMONT NEWHALL E O MUSEUM OF MODERN ART DE NOVA YORK
}

\author{
Diana de Abreu Dobranszky \\ Doutoranda do Departamento de Multimeios - Instituto de Artes - \\ Unicamp
}

O Departamento de Fotografia do Museum of Modern Art de Nova York teve papel decisivo na legitimação da fotografia como arte. Através de exposições e da constituição de uma coleção fotográfica Beaumont Newhall, o primeiro curador do departamento, difundiu a percepção da fotografia não como imagem mecânica mas como meio de expressão. Com o apoio da Capes, que nos concedeu uma bolsa de estágio de doutorado no exterior pudemos realizar uma pesquisa de um ano no museu. Com esse estudo esperamos elucidar o processo de aceitação da fotografia como arte dentro do espaço do museu.

O Museum of Modern Art de Nova York foi fundado em 1929 por três apreciadoras e colecionadoras da arte moderna: Lillie P. Bliss, Abby Aldrich Rockerfeller e Mary Quinn Sullivan. Após criar um comitê para a coordenação e administração do museu que iria nascer pediram a Paul Sachs, um desses membros, que indicasse uma pessoa talentosa e conhecedora da arte moderna para se tornar o primeiro diretor da instituição. Sachs, cujos ensinamentos sobre administração de museus em Harvard formaram uma geração inteira de curadores e diretores, indicou um jovem apreciador da arte moderna que foi responsável pelo rápido crescimento do MoMA: Alfred H. Barr, Jr.

Em seu projeto piloto do novo museu, Barr, que já havia incluído fotografia em suas aulas de arte moderna no Wellesley College, determinou que o museu deveria montar exposições que não apenas mostrassem, mas ensinassem a arte moderna para a população em geral. O principal papel do museu seria educar o público interessado em arte e mostrar-lhes as várias formas e vertentes da arte moderna produzida por artistas vivos e ativos. Além de conter departamentos tradicionais como de pintura, escultura e arquitetura, o MoMA, segundo ele, deveria abrigar também departamentos de cinema, desenho industrial, dança e fotografia. Mais que isso, esses departamentos deveriam estar em pé de igualdade com os tradicionais. Os 
departamentos não foram criados todos ao mesmo tempo; era preciso encontrar as pessoas certas para curar cada um deles. ${ }^{1}$

Quando Beaumont Newhall foi contratado como bibliotecário do museu em 1935, Iris Barry, que antes ocupava esse posto, havia sido indicada como curadora da recém criada Film Library. O Departamento de Fotografia ainda não existia, mas a fotografia já havia aparecido nas paredes do museu em algumas ocasiões. Em 1932 a exposição Murals by American Painters and Photographers apresentou a fotografia e pintura lado a lado. No entanto, isso não significou ainda uma equiparação em termos de valor estético. O foco da exposição eram os murais, como uma modalidade possível para ambas as artes. As críticas foram direcionadas ao talento da fotografia para esse meio e em nenhum momento tocou-se da questão da fotografia de arte. O objetivo do show era mostrar os murais como uma alternativa no embelezamento de edifícios

No ano seguinte outra exposição apresentou a fotografia: Walker Evans: Photographs of 19th Century Houses. Apesar de nos parecer uma individual do fotógrafo, esse show é considerado muito mais uma exposição de arquitetura do que de fotografias. Lincoln Kirstein, quem organizou a exposição, era amigo de Evans e o chamou para fotografar casas nos arredores de New England para um livro sobre casas americanas do século XIX que seu amigo arquiteto John Brooks Wheelwright iria escrever. Por outro lado, o interesse em expor certamente indica o reconhecimento de sua qualidade estética, o que levou Kirstein a sugerir à direção do museu que realizasse uma exposição com elas.

Em 1936 Barr orgnizou a exposição Fantastic Art, Dada, Surrealism que incluiu obras de Man Ray, Walker Evans e Hannah Hoch, entre outros. O importância dessa participação é devido à repercussão do show, um dos mais significativos da história do museu. Seu catálogo trazia um ensaio de Barr que iniciava uma tradição do MoMA em publicar livros com textos acadêmicos de fôlego que mais do que apresentar obras, forjavam uma visão do museu com relação à arte moderna.

No ano seguinte, 1937, a fotografia integraria essa tradição com a exposição Photography: 1839-1937. Com curadoria de Beaumont Newhall, essa foi a oportunidade da fotografia ser genuinamente aceita pelo museu

1 Para conhecer melhor os primeiros anos da história do Museum of Modern Art sugiro a leitura de LYNES, Russell. Good Old Modern: An Intimate Portrait of The Museum of Modern Art. New York: Atheneum, 1973. 
como meio de expressão legítimo da modernidade. O catálogo do show transformaria-se em um dos textos de maior influência no campo da fotografia do século XX. Foi revisado e ampliado inúmeras vezes por Newhall e é editado até os dias de hoje pelo museu. Newhall, ainda bibliotecário, foi abordado pelo diretor Alfred Barr nos corredores do museu sobre seu interesse em montar uma exposição sobre fotografia com o orçamento de US\$ 5 mil. Newhall pôde escolher o tema e viajou a Europa (França e Inglaterra) em busca de obras e conhecimento. O pesquisador estudava a fotografia desde os anos de estudante de história da arte em Harvard (onde cursou a disciplina de Paul Sachs sobre museus). Vinha escrevendo regularmente sobre o tema e publicando resenhas de livros da área. Barr, assim como todos que trabalhavam no MoMA, sabia do interesse de Beaumont pela fotografia e essa foi a oportunidade do funcionário provar que poderia curar exposições fotográficas de grande porte e que, principalmente, tinha conhecimento abrangente na área.

A exposição ocupou os quatro andares do museu (recentemente reformado) e apresentou mais de 800 peças, dentre elas equipamentos fotográficos antigos, e foi visitada por 30 mil pessoas. A maioria das obras dessa exposição histórica sobre a própria história da fotografia era de fotógrafos contemporâneos - devidamente de acordo com a política do MoMA em promover a arte do presente. Beaumont acreditava que a fotografia pura ("straight photography") era o estilo mais fiel à fotografia como arte, e privilegiou os fotógrafos adeptos. Essa atitude marcou toda a sua curadoria durante seus anos no MoMA. Mas não apenas a fotografia declaradamente de arte obteve espaço na exposição. Assim como Film und Foto, show realizado em Stuttgart em 1929, o curador apresentou no MoMA fotografias de imprensa, científicas, aéreas e filmes. Contudo, a abrangência dessa exposição não seria um padrão em seu trabalho.

Antes da criação do Departamento de Fotografia, o museu realizou mais uma exposição fotográfica em suas galerias: Walker Evans: American Photographs, em 1938, foi oficialmente ${ }^{2}$ considerada a primeira exposição individual de um fotógrafo no MoMA. A curadoria foi novamente de Lincoln Kirstein e o próprio fotógrafo montou o show. American Photographs também foi publicada em forma de livro e a repercussão foi grande. As obras no livro e na exposição foram organizadas em seqüências diferentes. No entanto, ambas mostraram uma visão dos Estados Unidos decadente e

\footnotetext{
${ }^{2}$ Segundo o press-release do museu e o próprio fotógrafo.
} 
desesperançoso. O fotógrafo também fez parte do grupo de fotógrafos contratados pela Farm Security Administration (FSA), que documentaram o país nos anos pós-depressão.Walker Evans foi o precursor de um estilo fotográfico americano que documenta sem romantismo os Estados Unidos.

Em fins de 1940, após cerca de dois anos de projetos e negociações, o Departamento de Fotografia foi anunciado e Beaumont Newhall foi apontado como curador. Desde 1938 ele e o fotógrafo Ansel Adams trocavam correspondências na tentativa de montar um projeto para o departamento. Beaumont havia lido e resenhado o livro Making $A$ Photograph de Adams publicado em 1935. No prefácio de seu livro o fotógrafo escreveu sobre a necessidade de um espaço institucional onde a fotografia poderia ser aprendida e pesquisada em seus próprios termos. $\mathrm{O}$ curador, então, logo procurou Adams para que o ajudasse no projeto. Outro personagem chave desse processo, principalmente na efetivação, foi David H. McAlpin, cuja fortuna e ligação com os Rockefellers renderiam um apoio de peso dentro do MoMA. Foi ele quem, secretamente, doou os US\$5 mil que possibilitaram a realização da exposição Photography 18391937. McAlpin era um entusiasta da fotografia e juntamente com o anúncio do novo departamento ele foi indicado como novo trustee do museu, assim como presidente do Comitê de Fotografia que também nascia nesse momento.

A primeira exposição montada pelo Departamento de Fotografia foi Sixty Photographs: A Survey of Camera Aesthetics, em 1940-41. A exposição, assim como o novo departamento foram destaque no Bulletin do MoMA (2 Vol. VIII, Dezembro-Janeiro 1940-1941). Nele, Alfred Barr escreveu que o museu estava abrindo espaço para aqueles que escolheram a fotografia como meio de expressão e que esse departamento sempre esteve no programa do MoMA. Na abertura da exposição Alfred Stieglitz esteve presente e disse a Newhall que este era um bom começo. Para ele, as

3 Fotógrafos: ABBOTT, Berenice; ADAMS, Ansel; ATGET, Èugene; BERNHARD, Ruth; BRADY, Matthew B.; CARTIER-BRESSON, Henri; EDGERTON, Dr. Harold; EVANS, Walker; GENTHE, Dr. Arnold; HILL, David Octavius; LANGE, Dorothea; LE SECQ, Henry; LEVITT, Helen; MODEL, Lisette; MOHOLY-NAGY; NORMAN, Dorothy; PORTER, Eliot F.; MAN RAY; SHEELER, Charles; STACKPOLE, Peter; STEICHEN, Peter; STIEGLITZ, Alfred; STRAND Paul; SWANK, Luke; WESTON, Brett; WESTON, Edward; WHITE, Clarence H; EMERSON, P. H.; O'SULLIVAN, T. H.; RODAKIEWICZ, Henwar. 
palavras de Barr eram muito importantes porque demonstravam um comprometimento do museu com a fotografia ${ }^{4}$.

Dentre as dezenas de exposições de fotografia do MoMA, podemos destacar algumas por sua relevância, exceção ou modelo. Algumas organizadas pelo departamento, outras não. De forma geral, as exposições dirigidas por Beaumont eram tradicionais: fotografias enquadradas com molduras, dispostas lado a lado; o que indica que sua intenção era de associar a fotografia com os meios tradicionais, para proporcionar a ela um espaço no meio das artes. Mas houveram experimentações e exceções.

Image of Freedom, de 1941-42, por exemplo, foi uma exposição de fotografias selecionadas através de um concurso promovido pelo museu. $\mathrm{O}$ folder de chamada para a seleção incitava os fotógrafos a criarem imagens que mostrassem o que os artistas acreditavam representar o que admiravam nos Estados Unidos. Jurados escolhidos pelo Departamento de Fotografia selecionaram 95 fotografia sem identificações; eram obras de 66 fotógrafos; alguns deles eram já conhecidos como André Kértesz e Brett Weston, mas a maioria é formada por fotógrafos amadores. Essa exposição nos parece ter sido interessante por apresentar uma amostragem do estilo de fotografia realizada nos EUA na época. Como não havia identificação dos fotógrafos os juizes escolheram as obras por sua qualidade individual, e não pelo conjunto de obra.

Outra exposição importante foi Photography in Progress, de 1944, que fez parte de uma grande mostra de arte moderna promovida pelo MoMA em seu 15o. aniversário (Art in Progress). Quem organizou-a foi Nancy Newhall, esposa de Beaumont. Durante a Segunda Guerra Mundial o museu se movimentou para ter um papel ativo de apoio ao governo americano. Beaumont Newhall, assim como outros funcionários e membros do MoMA, serviu o exército. Entre meados de 1942 e de $1945^{5}$ ele era um dos interpretadores de imagens aéreas. Seu cargo foi ocupado em caráter temporário por sua esposa, como curadora atuante. Nancy, ao lado de Beaumont, conheceu muitos fotógrafos e estudou o meio fotográfico. Era amiga de Stieglitz, de Adams, de Weston e sobre eles escreveu. Seu trabalho durante os anos de ausência do curador foi alinhado

4 Ansel Adams: Lettlers and Images 1916-1984. Ed. Alinder, Mary Street \& Stillman, Andrea Gray. A New York Graphic Society Book, 1988, p. 123-124.

5 De Agosto de 1942 a Outubro de 1945. 
ao dele, com quem se correspondia constantemente - Beaumont Newhall ainda era oficialmente o curador do Departamento de Fotografia.

A maioria dos fotógrafos expostos em Photography in Progress tinham, a essa altura, obras na coleção do museu $^{6}$, e representavam o que o departamento acreditava ser $\mathrm{o}$ melhor da produção fotográfica contemporânea americana e européia, assim como alguns representantes do século XIX. Uma crítica constantemente feita ao MoMA foi o privilégio dado às essas regiões. Em sua pesquisa para a exposição Photography 18391937 Newhall pôde apenas pesquisar na Europa e Estados Unidos. Como esse estudo constitui a principal formação do curador a tendência se esclarece. Mas esse mesmo fato ocorre com os demais departamentos; era uma constante nas exposições do museu que teve dificuldade em estar atento à arte produzida nos demais hemisférios e continentes. No entanto, o trabalho dos curadores foi primordial para o melhor entendimento da arte de sua época.

Duas individuais organizadas pelo departamento merecem destaque: Photographs 1915-1945 by Paul Strand (1945) e The Photographs of Edward Weston (1946). Elas seriam o começo de uma série de individuais com catálogos bem elaborados que os Newhalls haviam planejado. Contudo, a indicação de Edward Steichen como diretor do departamento em 1947 e a conseqüente saída de Beaumont interromperam os planos. Ainda houve uma individual de Henri-Cartier Bresson em cujo catálogo há um ensaio de Beaumont, mas a troca de comando já havia ocorrido. Os shows de Strand e Weston eram retrospectivas de suas obras e quem escreveu sobre eles nos catálogos foi Nancy. Seus ensaios bem elaborados?

6 ABBOTT, Berenice; ADAMS, Ansel; ALVAREZ-BRAVO, Manuel; ATGET, Èugene; BRADY, Matthew B.; BREITENBACH, Josef; BRUGUIÉRE, Francis; CAMERON, Julia Margaret; CARTIER-BRESSON, Henri; CLOUGH, Stanley; CUNNINGHAM, Imoge; EDGERTON, Harold E.; EMERSON, P. H.; ENGEL, Morris; EVANS, Walker; FEININGER, Andreas; WEEGEE; FENTON, Roger; GENTHE, Arnold; HÁZ, Nicolas; HILL, David Octavius; HINE, Lewis; JACKSON, William Henry; LANGE, Dorothea; LEE, Dudley; LE SEQC, Henry; LEVITT, Helen; MARTIN, Paul; MODEL, Lisette; MOHOLY-NAGY; MORGAN, Barbara; MUYBRIDGE, Eadweard; OUTERBRIDGE, Paul; PORTER, Eliot; ROTHSTEIN, Arthur; RUSSELL, A. J.; SHEELER, Charles; SIEGEL, Arthur; TALBOT, William Henry Fox; VANDIVERT, William; WESTON, Brett; WESTON, Edward; WHITE, Clarence H; WRIGHT, Cedric; ELLIOT, Andrew; GARDNER, Alexander; KIRCHER, Athanasius; O'SULLIVAN, T. H. \& BELL, W.; STIEGLITZ, Alfred; STRAND, Paul; WOOD \& GIBSON; ANTHONY, Edward; BIERSTADT, Charles; HILLERS, John; SOUTHWORTH \& HAWES; WATKINS, C. E.; ZIMMERMAN, Charles A.; GEORGE, H. B. \& EDWARDS, Ernest.

7 NEWHALL, Nancy. From Adams to Stieglitz: Pioneers of Modern Photography. New York: Aperture, 1999. 
metafóricos e criativos tornaram-na conhecida e respeitada no mundo da fotografia.

Como já mencionamos acima, o MoMA fez parte do que ficou conhecido como War Effort, um movimento de apoio ao governo americano. Dentre as exposições fotográficas sobre a guerra - foram nove no total - Road to Victory, de 1942, foi a de maior repercussão. O responsável por ela foi Edward Steichen, comandante da Marinha Americana e fotógrafo que esteve presente na história da fotografia americana em todo o século XX. O show mostrou 150 fotografias feitas por agências e instituições do governo americano e por agências jornalísticas. São muitas as diferenças com relação as demais exibições de fotografias do MoMA. Primeiramente, não há créditos aos fotógrafos e juntamente com as imagens haviam frases que formavam um discurso sobre a guerra. O display das fotografias foi projetado por Herbert Bayer: as imagens foram ampliadas em grande formato e expostas de forma não convencional, proporcionando um espetáculo para o público. Steichen também organizou Power in the Pacific, em 1945, de forma semelhante a Road to Victory. O nome de Steichen, o grande público e atenção de ambas as exposições citadas acima certamente incentivaram os administradores do museu a escolhê-lo como diretor do Departamento de Fotografia com o objetivo de atrair mais fundos e público para o departamento.

Fazem parte dos anos Newhall exposições sobre dança (Dancers in Movement: Photographs by Gjon Mili, 1942; Modern American Dance, 1945), sobre a criação fotográfica (How To Make a Photogram: Painting with Light, em 1942; Action Photography, em 1943; Creative Photography, em 1945), sobre novos talentos (Helen Levitt: Photographs of Children, em 1943; New Workers, em 1944; New Photographers, em 1946), outras sobre grandes mestres (David Octavius Hill: Portrait Photographs 1843-1848, em 1941; New Acquisitions: Photographs by Alfred Stieglitro, em 1942), e temáticas (Photographs of of the Civil War and the American Frontier, em 1942; 100 Years of Portrait Photography, em 1943; Pictorialism in Transition, em 1944; French Photographs: Daguerre to Atget, em 1945), entre outras.

A coleção adquirira pelo museu desde sua inauguração ampliou-se de forma significativa durante a curadoria de Beaumont Newhall. São mais de 160 fotógrafos representados por quase mil e trezentas obras. A maior parte delas são de fotógrafos adeptos da straight photography, do sexo masculino e de nacionalidade americana.

Os dados encontrados através da análise das exposições e da coleção do Departamento de Fotografia nos possibilitam traçar o perfil da 
curadoria de Beaumont Newhall e de suas convicções sobre o que seria a melhor fotografia de sua época. Textos de catálogos e press-releases, juntamente com os dados referidos acima, formam discursos verbais e não verbais que nos fazem compreender esse trecho da história da fotografia. Tal análise detalhada será resultado de nossa tese de doutorado que será apresentada em breve. Esse artigo nos dá indicativos como a preferência de Newhall pela straight photography, e como a influência da Segunda Guerra Mundial no programa do museu e consequentemente do departamento. Newhall abriu caminhos que foram seguidos por outros e que mondaram a apresentação da fotografia como arte nos museu. O MoMA teve papel importante na aceitação da fotografia de arte dentro dos museus de arte, espaço que precisou ser conquistado como legitimação institucional.

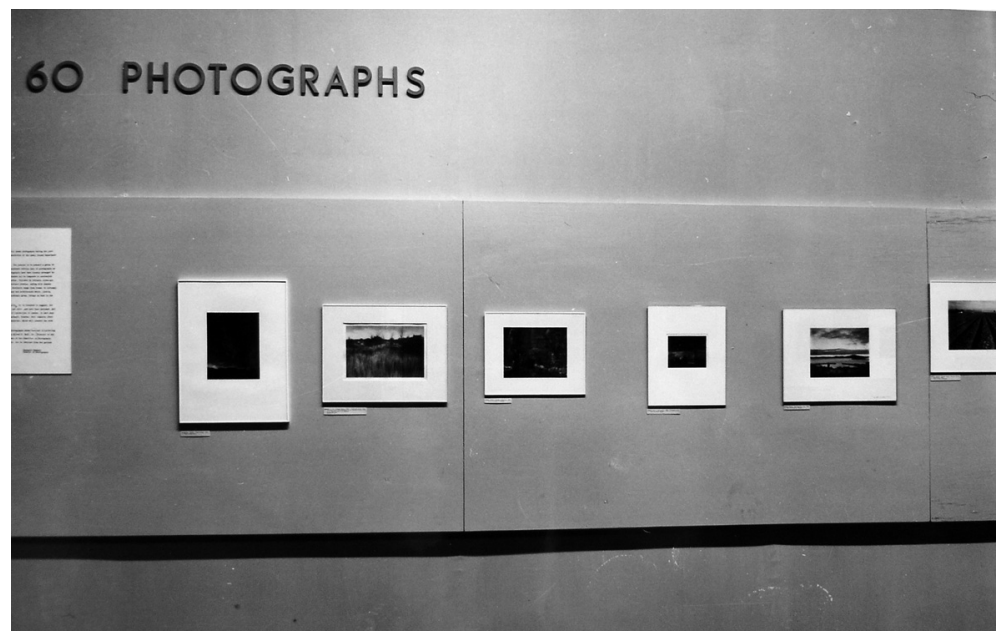

Exposição Sixty Photographs: A Survey of Camera Aesthetics, de 1940-41. 


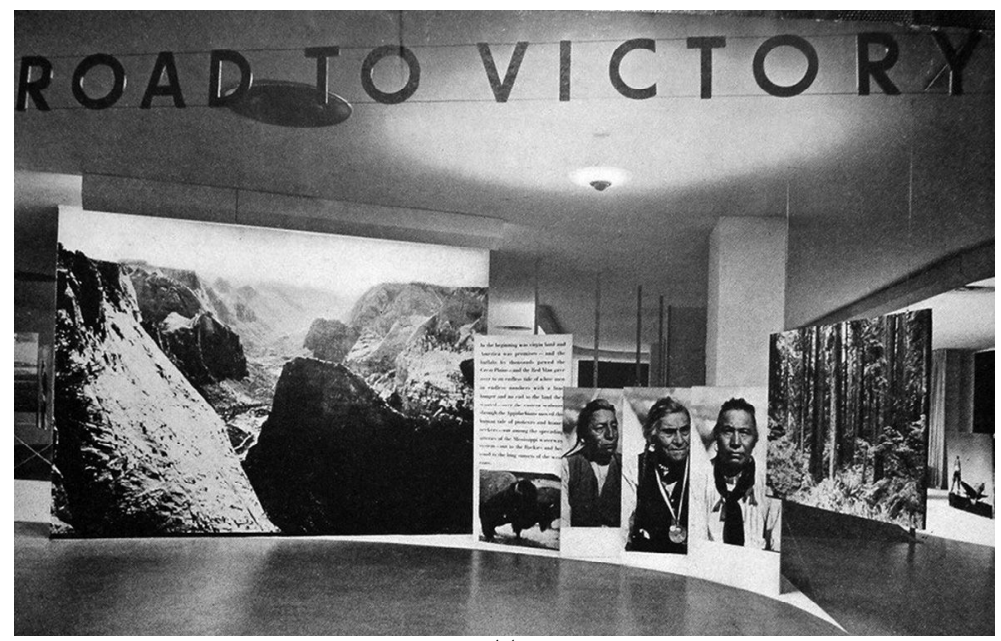

Exposição Road To Victory, de 1942.

\section{Bibliografia}

Ansel Adams: Lettlers and Images 1916-1984. Ed. Alinder, Mary Street \& Stillman, Andrea Gray. A New York Graphic Society Book, 1988.

LYNES, Russell. Good Old Modern: An Intimate Portrait of the Museum of Modern Art. New York: Atheneum, 1973.

NEWHALL, Beaumont. Photography 1839-1937. New York: The Museum of Modern Art, 1937.

NEWHALL, Nancy. From Adams to Stieglitz: Pioneers of Modern Photography. New York: Aperture, 1999. 